\title{
A Proposed Plan to Implement Core Competencies and High-Impact Educational Practices in Saudi Universities in Light of The Experiences of Some International Universities
}

\author{
Hisham Saad Zaghloul \\ Department of Self-Development Skills, Deanship of Preparatory Year \& Supportive Studies, Northern Border University, \\ Arar, Saudi Arabia \\ Jehan Abd-Alwahab Alandejani \\ Department of Self-Development Skills, Deanship of Preparatory Year \& Supportive Studies, Northern Border University, \\ Arar, Saudi Arabia \\ Yousef Khader Sanajlawe \\ Department of Computer Science, Deanship of Preparatory Year \& Supportive Studies, Northern Border University, Arar, \\ Saudi Arabia
}

\begin{abstract}
Although first-year seminars and experiences have been widely considered as a high-impact educational practice, which is used to enhance academic performance, retention, and acquisition of critical 21 st Century outcomes, first-year seminars and experiences tend to be loosely defined and assessed in prior studies to highlight its importance in improving the education process as a whole; therefore, this study aims to assess the impact of highimpact educational practices (HIEPs) in preparatory years in Saudi Arabia and international universities, then proposing a plan for efficiently implementing HIEPs in higher education institutions. To achieve that, case-based analysis and the survey analysis method were used wherein qualitative examination of practices in University of California and Indiana University and quantitative assessment of (130) faculty members and students' perception of Northern Border University was conducted. Case analysis revealed that international universities implement practices suited for their institution and not the stated one i.e., Health Professional Advising Center, undergraduate research programs, or Capital academic internship program in University California, while undergraduate research, service-learning practices, or learning community in Indiana University. Survey analysis on the other hand stated that consisting of the above (20_ years respondents, implementation of core competencies and HIEPs helps in exploring relevant issues and controversies, linking of knowledge and skills, and better students and faculty bond which raise teaching and learning experience. Results revealed that core competencies and HIEPs have a significant influence on the teaching and learning outcomes. As result, an efficient implementation the plan is proposed to activate HIEPs and core competencies in the preparatory year at Saudi universities.
\end{abstract}

Keywords - Core competencies, High Impact Educational Practices (HIEPs), First year, International experiences, Saudi Arabia.

\section{INTRODUCTION}

Development in higher education in Saudi Arabia

With the evolution of the economy, there has been growth in the role of technology in the educational system. The job market has upgraded to the mechanism wherein possession of highly technical skills, adaptability to rapidly changing environment, and adjustability with different teams or cultural environment has become criteria of evaluating the capabilities of an individual. In order to cope up with the changing demands of the job market, there is a need of having a major restructuring in the higher educational level by emphasizing skills and technology via combining skills or competencies and knowledge as the measurement of educational delivery output [1]. Even the teaching and learning process in universities has shifted to being more focused on working through modifying the course curriculum with the usage of core competencies (i.e., activities are planned in a format to provide students with the skills required for becoming successful employees and learners in every aspect of their life). To enhance the learning experience of students and increase the retention rate and student engagement, there has been a promotion of High Impact Educational Practices (HIEPs) implementation in the higher education institutes [2].

The role of preparatory year in higher education programs in Saudi Arabia

The development of higher education institutions in Saudi Arabia is dependent on revenues derived from oil 
exports, with recent programs aimed at enhancing diversity and quality education. And the advancements in the 20th century provided many educational methods, technologies, and innovations that certainly changed the education process $[3,4$, 5]. The current challenges faced by the education industry include growing demand for skill development, securing crucial resources, and meeting the country's workforce requirement [6]. These challenges were addressed in the Saudi government's (2016) program Vision (2030), which aimed at bringing the country's education system at par with the most advanced countries across the world. Universities herein responded by internationalizing higher education and developing world-class universities to establish a partnership with specialized training centers for increasing the efficiency of graduates and providing supporting training processes to enhance learning [7].

Among these practices, one more aspect that emerged as a mechanism of providing a better educational experience to students is the inclusion of the preparatory year in higher education programs. The preparatory program refers to a program designed for the first-year higher education students to have a smooth transition from the secondary school education level of higher education. Providing the language courses and other foundational undergraduate courses, the preparatory year laid the groundwork for the other higher education courses [8]. Though many foundational courses are included in this year the preparatory year is completely different from the high education classes as they don't work on providing technical information to the students, instead, it's like a two-semester program for supporting the adjustment of students in the new academic environment by working on language skills, familiarizing students with local customs/ cultures/ teaching system, introducing them to basic notions and theories, and building in confidence for following years study [9, 10]. As the preparatory year is like an introductory program for students, thus many universities now work on implementing them in their educational curriculum [9]. Northern Border University (NBU) is a public university located in Arar, Saudi Arabia and boasts of around (16) colleges, (4) campuses, and more than (15000) undergraduate students $[11,12]$. In accordance with the Vision (2030), NBU determined that competencies and teaching practices should be designed in a way to align workforce directions with regional workforce needs [13]. For this, they initiated extracurricular activities to attain core competencies at the preparatory year. Herein, the preparatory year is described as the first year of university life wherein skills courses are provided that enable qualification of students for the specialized course. However, institutional programs are structured with traditional teaching and lack of opportunities to refine the skills of students [14].

The importance of applying high impact educational practices in higher education

The changing needs of the job market have created an environment wherein the priority is to not gain just the conceptual and theoretical knowledge, but instead, the workforce should be competent enough to upgrade themselves according to the changing demand [15]. Several researchers have opined that Saudi Arabia's education system with its reliance on natural resources is continuously working towards diversifying its education system, but depending on the traditional mode of teaching and learning and unavailability of adequate facilities hinder the pace of growth [16, 17, 18, 19]. The major shortcoming in these studies is that although they provide a detailed assessment of the education system of Saudi Arabia and their challenges, not many identify contemporary strategies, which can be applied successfully to overcome these drawbacks or their impact. Further, not many studies focus on the role of preparatory year in retaining students and providing a better educational experience, even though its implementation is a key higher education program in Saudi Arabia. Hence, there is a need to examine the current situation of education in Saudi Arabia and evaluate the impact of High Impact Educational Practices (HIEPs), one such contemporary strategy, on its quality of education, particularly for students in preparatory years in NBU. Preparatory years are crucial in a student's academic background they become familiar with the academic environment of a university, are exposed to these high impact educational practices firstly, and are witnessing the change in educational level from basics to technical. follows:

In this regard, the objectives of this study are as

- To assess the development of HIEPs in international universities (i.e., Indiana University and the University of California).

- To determine the perceptions of teachers and students toward applying HIEPs in higher education.

- To propose a plan to implement core competencies and high-impact educational practices in Saudi universities.

\section{LITERATURE REVIEW}

The rise in the role of information technology and the movement of the global economy towards big data has resulted in modulation in higher educational institutions. New mechanisms of education developed in higher education are crafted, which aim at making students competent for the changing demands of the job market. For this, it is essential to utilize high impact educational practices and modifying the teaching process by changing core competencies [1]. Saudi Arabia in recent years has changed its approach towards higher education in order to make it more competitive, but still the constant reliance on theoretical knowledge and non-availability of technical expertise, which is detrimental to learning. Thus, there is a need for the role of core competencies and highimpact educational practices to be examined to determine the relevant changes required [18]. Below sub-sections, thus explain the concepts of core competencies and high-impact educational practices.

\section{The significance of core competencies in higher education}

The concept of core competencies defined by C.K. Prahalad and Garry Hamel from (1990) article "The Core Competence of the Corporation" as the collective learning of the organization through coordinated diverse skills and ability to integrate multiple technology streams [20]. It has been increasingly applied in the context of organizational success in recent years. Keeping with this trend, universities across the 
world are aligning their core competencies with higher education needs, which consist of skill development, training, qualifications, and curriculums. Global governments believe to be essential for building in the flexible workforce and provide successful lifelong learning [1].

Core competencies, identify skills that a student needs for becoming a learner in the field of study, successful at work and other aspects of life. Core competencies are the combination of attributes like problem-solving, IT skills, working with others, learning how to learn, subject-specific competencies, and communication which are required for having successful professional performance [1]. In today's highly competitive work environment, employers, want their workforce to have the ability to update their skills and develop new ones regularly, be adaptable, think critically, and deal with problematic situations with new solutions to accomplish goals [21]. Firms are able to derive competitive advantages by using applying core competencies in a wide variety of markets and products. Thus, its implementation in higher education is essential [22].

However, an alternative school of thought offers a counter-argument on the application of core competencies. Although the usage of core competencies is essential, these studies advocate that as graduates tend to switch from one employability opportunity to another for personal growth, the organizations hiring them also provide certain training for enhancing their skill set However, when these employees leave the organization, it results in losses, as skills are nontransferable [21, 23]. With too much reliance on certain people only for core competencies, there is a barrier to imitation and the difficulty in finding substitution, which hampers sustainability [24]. Even the changing business environment needs continuous up-gradation is a skill set too but the rigidity in skillset leads to issues with differentiation and adaptability. Further, when an organization or an institute has the limited availability of resources and materials, the focus on the enhancement of skills is not possible [22].

Despite the existing challenges, core competencies help in creating competitive advantage, provide potential access to a variety of markets, make a significant contribution, difficult to imitate, pave way for a long run above-average performance, improve long term success chances, and enables the skills to meet with market opportunities [22, 23, 25]. Further, promoting the concentration of people in areas deriving higher returns, core competencies help students be more innovative. Core competencies build on people's fundamentals/basics, think conceptually, develop people skills in a competitive environment, enable appropriate decision making, work in teams, share information, work in social or religious or cultural diversity, improve productivity, and minimize unemployment [22].

\section{The significance of High Impact Educational Practices in} higher education

HIEPs are the designs or techniques used for learning and teaching that are beneficial for successful learning and improving student engagement [26]. These practices are the collection of strategies providing deep learning experience via (11) different HIEPs i.e., first-year experiences, common intellectual experience, learning communities, writing- intensive courses, collaborative assignments and projects, undergraduate research, diversity/global learning, internships, service-learning, or community-based learning, capstone courses and projects, and ePortfolios [27, 28].

The education industry is currently grappling with several challenges such as a high drop-out rate, decreasing student engagement, and the immense pressure to optimize courses $[29,30,31]$. Therefore, universities are working towards encouraging the utilization of one or more HIEPs to improve active learning [31]. Through advanced pedagogy and intentional program design, these practices narrow the gap in achievements across students, enhance student learning, contribute to grade points improvements, and earn degrees quickly [29]. Incorporation of these practices brings guidance and structure to the learning, helps students become meta learners, use small groups powerfully, and build a relationship that contributes to improving attitude and mindset. Therefore, HIEPs implementation is essential [32, 33].

Implementation of HIEPs is challenging, as it is difficult to demonstrate their financial benefits backed by increasing graduation rates, having the acknowledgment of the institutional data of student learning level and their needs for practicing HIEPs, and regularly change the reward system of faculties and staff to increase their involvement in HIEPs [34]. Apart from this, successful implementation of HIEPs requires performance expected to be set at a high level and spend significant time and effort which itself is a challenging part [35]. Often, institutions consider that implementation of a large number of practices could yield better graduation rates, but quantity is not actually related to it [36]. In the case of HIEPs, compromise is done at regular teaching levels and courses, which in turn lead to hampering the learning experience of students [37].

The usage of HIEPs contributes by increasing the GPA and persistence of students; provide a deep approach to learning, increase writing and critical thinking skills, more student-faculty interaction, high student engagement, and greater diversity appreciation [38]. Emphasizing the practices wherein learning by doing concept is applied, HIEPs make classroom learning relevant through the opportunity of applying the knowledge to the real-world [39]. Further, HIEPs have selfreported gain in learning and personal development form, have a better understanding of the underlying meaning of information and have derived regular feedback for changes and upgradation [35].

\section{An empirical analysis of related works}

The concept of core competencies and HEIPs is not a new concept. Many researchers have focused on examining the role of these practices at the higher education level and many studies have focused on assessing the perception of managers and students in the global business world for drawing empirical conclusions regarding HIEPs. However, not many studies directed their research on the assessment of preparatory year students' perception or determining strategies, which could help in better implementation of these practices along with coping with existing drawbacks. This section examines previous works to address the identified research gap.

The relationship between core competencies, organizational performance, and competitive advantage is 
investigated in [40]. The examination of (64) managers' perception depicted that core competencies have a strong positive influence on competitive advantage, which in turn significantly influence organizational performance. In addition, the (267) undergraduate students' perception of Midwestern university in the U.S. was studied in $[41,42]$, by building in the relationship between high impact practices and student engagement. The practices like undergraduate research, service learning, group assignments, sequence courses, learning communities, and close faculty mentor does have a significant influence on raising the engagement level of students. The authors in [32] focused on deriving the influence of high impact practices on the educational outcomes by studying the dataset collected from (4193) first-year students of (17) institutions. The analysis revealed that high impact practices were beneficial for students. Among all practices, the undergraduate research and active and collaborative learning were especially beneficial while practices like study abroad, internship, and capstone course or experience have a lower level of positive impact on learning outcomes of students.

The study in [43] focused on examining the role of core competencies in organizational performance by examining datasets collected from (200) managers of (10) private banks. The analysis of the dataset defined that the usage of core competencies contributes to improving the effectiveness of organizational performance. Moreover, the study in [44] focused on understanding the role of high impact practices on student retention. Except for the service-learning, communitybased learning, and learning communities all other high-impact practices tend to have a significant role in affecting the retention level of students. Besides, the authors in [45] focused on determining the influence of intensive faculty training programs on the learning and teaching knowledge, skills, and attitudes of female and male faculties. The examination of (36) faculty members (22 females and 14 males) shows that these training programs could improve the skills, attitudes, and knowledge.

The dataset of (4) public institutions in the U.S. was utilized in [46] in order to build the relationship between high impact practices and academic outcome. For the first and secondary year students among practices like first-year seminars/experiences, writing-intensive courses, internships, diversity/global learning, collaborative assignments and projects, undergraduate research, and servicelearning/community-based learning; the collaborative assignments and projects have proven to be most significant. The study in [47] used the received sample from (21) individuals (professional staff members and business faculty with active participation in programs) of (28) U.S. School to examine the impact of innovative high impact activities and determined that with integration in the business program, these practices contribute in raising student engagement beyond traditional programs learning.

The major shortcoming of the above studies is that although they explore the impact of core competencies and HEIPs as well as the perception of teachers and students, they have not studied preparatory year students who mainly witness the change in education structure from theoretical to practical aspects. Furthermore, none of them has identified the strategies, which would help in overcoming the existing issues. Thus, this study academically and practically contributes to enriching the literature on this topic along with suggesting the mechanism of providing better teaching and learning experience in higher educational institutions of Saudi Arabia.

Table 1. Synthetic analysis of previous studies

\begin{tabular}{|c|c|c|c|c|}
\hline No. & $\begin{array}{r}\text { Purpose } \\
\end{array}$ & Methodology & Finding & Source \\
\hline 1. & $\begin{array}{l}\text { To investigate the relationship } \\
\text { between core competence, } \\
\text { competitive advantage, and } \\
\text { organizational performance }\end{array}$ & $\begin{array}{l}\text { Multiple regression-based analysis of } \\
\text { (64) managers in the paint industry }\end{array}$ & $\begin{array}{l}\text { The core competencies have a positive } \\
\text { effect on the organizational } \\
\text { performance and competitive } \\
\text { advantage of industries }\end{array}$ & {$[40]$} \\
\hline 2. & $\begin{array}{l}\text { To determine the relationship } \\
\text { between HIEPS and student } \\
\text { engagement/interaction }\end{array}$ & $\begin{array}{l}\text { Perception of (267) undergraduate } \\
\text { students in the US using Hierarchical } \\
\text { Linear Regression }\end{array}$ & $\begin{array}{l}\text { HIEPs have a significant positive } \\
\text { influence on the student engagement } \\
\text { or interaction level }\end{array}$ & [41] \\
\hline 4. & $\begin{array}{l}\text { To determine the impact of core } \\
\text { competencies on organizational } \\
\text { performance }\end{array}$ & $\begin{array}{l}\text { Examination of (200) managers in Iraqi } \\
\text { market financial assets using t-test, } \\
\text { simple regression coefficient, mean, } \\
\text { coefficient variation test, Friedman, and } \\
\text { simple linear correlation. }\end{array}$ & $\begin{array}{l}\text { There is a significant correlation } \\
\text { between core competencies and } \\
\text { organizational performance as core } \\
\text { competencies improve organizational } \\
\text { performance effectiveness. }\end{array}$ & [43] \\
\hline 6. & $\begin{array}{l}\text { To assess the intensive faculty } \\
\text { training program impact on the } \\
\text { teaching and learning attitude, } \\
\text { knowledge, and skills for female } \\
\text { and male faculty. }\end{array}$ & $\begin{array}{l}\text { Quantitative analysis for }(36) \\
\text { participants is done using paired t-test. }\end{array}$ & $\begin{array}{l}\text { The analysis depicts that usage of } \\
\text { these training programs and practices } \\
\text { could significantly contribute to the } \\
\text { improvement of knowledge, skills, } \\
\text { and attitude. }\end{array}$ & [45] \\
\hline
\end{tabular}




\begin{tabular}{|l|l|l|l|l|}
\hline 7. & $\begin{array}{l}\text { To determine the influence of high } \\
\text { impact practices on the academic } \\
\text { achievement of first-year and } \\
\text { second-year students. }\end{array}$ & $\begin{array}{l}\text { Examination of (652) undergraduate } \\
\text { students using the Mann-Whitney U test } \\
\text { and chi-square test. }\end{array}$ & $\begin{array}{l}\text { The volume of HIEPs is positively } \\
\text { linked with academic achievement } \\
\text { (GPA). [46] }\end{array}$ \\
\hline 8. & $\begin{array}{l}\text { To understand the high impact } \\
\text { activities integration with student } \\
\text { engagement level beyond } \\
\text { traditional classrooms. }\end{array}$ & $\begin{array}{l}\text { The perception of (21) individuals was } \\
\text { examined using the chi-squared test and } \\
\text { demographic analysis. }\end{array}$ & $\begin{array}{l}\text { The analysis reveals that high impact } \\
\text { practices have a contribution to raising } \\
\text { student engagement level. }\end{array}$ \\
\hline
\end{tabular}

- Competitive advantage.

- Access to variety of markets.

- Difficult to imitate.

- Long run above average performance.

- Long-term success chances.

- Meet with market opportunities.

- Creating innovative environment.

- Appropriate decision making.

- Team based working.

- Ability to share information,

- Promote working in social or religious or cultural diversity.

- Improving productivity.

- Minimizing unemployment.

- Persistence of students.

- Deep approach of learning.

- Increase in academic performance.

- Increase in writing and critical thinking skills.

- Better student-faculty interaction.

- High student engagement.

- Diversity appreciation.

- Opportunity of applying the theoretical knowledge to real world.

- Gain in learning and personal development.

- Better understanding of information.

- Regular changes and upgradation.

Benefits

Core Competencies

Types

Teaching and Learning outcomes

Benefits

High-Impact
Educational Practices

Types
- Problem solving/ Efficiency of critical thinking.

- Numeracy.

- IT skills/ Efficiency of digital culture.

- Working with others/ Efficiency of teamwork.

- Learning how to learn/ Efficiency of self-management.

- Communication.

- Subject specific competencies.
- First year experiences.

- Common intellectual experience.

- Learning communities.

- Writing intensive courses.

- Collaborative assignments and projects.

- Undergraduate research.

- Diversity/global learning.

- Internships.

- Service learning or communitybased learning.

- Capstone courses and projects.

- EPortfolios.

Fig. 1. Conceptual framework

Based on the information derives from previous studies and the examination of the core competencies and highimpact educational practices concept, the information is derived about the challenges, role, limitation, weaknesses, and strengths of different core competencies and HIEPs. Thus, the above figure works on providing a brief outlook of the concepts and have the statement of the aspects that would be used by the researcher in the analysis process. It shows (7) core competencies i.e., numeracy, problem-solving, IT skills, learning how to learn, subject-specific competencies working with others, and communication; the core competencies help in improving productivity, minimizing unemployment, providing a competitive advantage, or creating an innovative environment. While high impact practices of (11) types i.e. common intellectual experience, First-year experiences, writing-intensive courses, learning communities, undergraduate research, collaborative assignments and projects, diversity/global learning, service-learning or community-based learning, internships, capstone courses and projects, and ePortfolios; the HIEPs helps in better understanding of information, the persistence of students, providing deep learning to students, high student engagement, or providing opportunity to apply theoretical knowledge real world. The conceptual framework proposes that with a 
contribution in influencing the capability and experience of students, there is the impact of core competencies and HIEPs on the teaching and learning of students.

\section{METHODOLOGY}

The research methodology of a study defines the blueprint of the study by stating the procedure of examining the dataset and fulfilling the purpose of the study. With the aim of the study to assess and compare the impact of high impact educational practices, this section presents the process of working.

Research Type

The research type of study defines the mechanism used by the researcher as per his perspective on the working. Putting forward the plan of compiling, collecting dataset, and analyzing it, the research type defines the base of analysis [45]. In this research, a mixed-method is used. i.e., a case study analysis is used for qualitative examination to explore the status of implementing the HIEPs in international universities and determine the strengths and weaknesses of the way that they implement the HIEPs. Besides, an explanatory research design using a questionnaire is used to conduct the quantitative analysis to evaluate the effectiveness of implementing the HIEPs in NBU.

\section{Data Type}

The data type for the study defines the information used by the researcher for deriving relevant information to fulfill research objectives. As this study examines descriptively the information about high impact educational and core competencies along with their implementation in an international university, thus secondary qualitative data is used while for the determination of impact in Saudi Arabian universities the primary quantitative dataset was used.

\section{Sampling Plan}

The sampling plan deals with the specification of eligibility conditions for the respondents to be included in a particular study. For determining the reliability of high impact practices around the world, the study focuses on qualitative analysis of the core competencies and high impact practices by reviewing the information derived from bulletins, websites, research published in the field, and accredited reports. Herein, the analysis examines the perspectives of staff from the University of California and Indiana University. Secondly, for the quantitative analysis, the study used a close-ended questionnaire for collecting the perception from (130) students and academic members from preparatory years.

Herein, only preparatory year students and faculty members were included. The formulated questionnaire is divided into (3) categories (i.e., demographic), knowledge about the concept (Background), and inferential for impact assessment; to identify the weakness, strengths, opportunities, and threats of high impact practices. Besides, the random sampling method was used for selecting the respondents from the given population of students. This technique helps in reducing human bias in the process of data collection, enhancing the reliability of the data. Thus, using random sampling, the collection of the dataset is done from the first preparatory year faculties and students from Northern Border University in four academic departments: English Language Skills, Basic Sciences, Computer Skills, and Self-Development Skills Department.

\section{Reliability Assessment}

Reliability means the constancy of measurement instruments over time. In this study, the constructs in the survey will be weighted by a multiple-item scale. Hence, internal consistency will be applied to estimate the reliability of this research by measuring correlations among items within a scale of a given construct. Cronbach's alpha will be applied to determine the internal reliability of a multiple items scale [48]. Cronbach's alpha value ranges between 0 and 1, where coefficient alpha is closer to 1 , being the greater degree of items' reliability.

However, researchers have never agreed on an adequate cut-off value for reliability. Many supposed that a value of 0.7 or more is genuinely adequate [49], while some have asserted the value of 0.6 as an appropriate value and others claimed that a value above 0.5 is low but acceptable [50].

Reliability means the constancy of measurement instruments over time. In this study, the constructs in the survey will be weighted by a multiple-item scale. Hence, internal consistency will be applied to estimate the reliability of this research by measuring correlations among items within a scale of a given construct. Cronbach's alpha will be applied to determine the internal reliability of a multiple items scale [48]. Cronbach's alpha value ranges between 0 and 1, where coefficient alpha is closer to 1 , being the greater degree of items' reliability.

However, researchers have never agreed on an adequate cut-off value for reliability. Many supposed that a value of 0.7 or more is genuinely adequate [49], while some have asserted the value of 0.6 as appropriate and others claimed that a value above 0.5 is low but acceptable. In [51], a rule of thumb for Cronbach's alpha classifying reliability values, as pointed in Table 2.

Table 2. Cronbach's alpha rules

\begin{tabular}{|l|c|}
\hline \multicolumn{1}{|c|}{ Cronbach's Alpha } & Consistency \\
\hline Less than or equal to 0.9 & Excellent \\
\hline More than or equal 0.8 and less than 0.9 & Good \\
\hline More than or equal 0.7 and less than 0.8 & Acceptable \\
\hline More than or equal 0.6 and less than 0.7 & Questionable \\
\hline More than or equal 0.5 and less than 0.6 & Poor \\
\hline Less than 0.5 & Unacceptable \\
\hline
\end{tabular}

\section{Validity Assessment}

Validity indicates if the items of the scale are accurately weighing the relevant instrument with no extra features. Content validity will be tested in a pilot study. According to [52], construct validity which is interested in the extent to which and how well items measure a theoretical construct, is regarded as very significant it needs to be measured to confirm the validity. Factor analysis is one of the statistical 
tools that can be utilized to evaluate the construct validity. Although all selected constructs in this research will be adapted from earlier studies and have been approved by factor analysis, this analysis will frequently be conducted as the measurement of constructs will be translated from its primary language (English) into Arabic. Secondly, factor analysis will be employed to affirm validity to popularize the conclusion of this research.

\section{Data analysis methods}

For fulfilling the objective, the collected secondary data was reviewed via content analysis method i.e., case Based analysis while the primary data collected from faculty members and student's perception is examined using frequency analysis, correlation, and regression analysis. Herein, at (5\%) level of significance, the below stated hypothesis was examined using SPSS software.

$\mathbf{H}_{0}$ : Core competencies and High impact educational practices do not have a significant influence on the teaching and learning outcome.

H1: Core competencies and High impact educational practices have a significant influence on the teaching and learning outcome.

\section{Ethical Considerations}

Data collected from faculty members and students was safeguarded with a password-protected device along with securing privacy by not disclosing any personal details. Bias is eliminated from the survey data by verifying the validity of the questionnaire using Cronbach's alpha analysis, which states that the Cronbach's alpha value must be more than (0.7) for the questionnaire to be valid. The results of this test are presented in the analysis. Further, data collected for case study analysis was reliable as credible sources of secondary data were used such as official websites of the universities and the governments.

\section{Data analysis}

With the focus on determining the role of high impact practices and core competencies in the higher education for Saudi Arabian universities and international universities, the below section presents the case-based analysis of the University of California and Indiana University followed by survey analysis based on the perception of students and faculty members of Northern Border University.

\section{Case Analysis}

The case-based analysis refers to a method of having a systematic generation of information and the examination of different cases like people, events, projects, communities, institutions, programs, or policies [53].

Since the publishing of a book on the importance of HIEPs by George Kuh (2008), institutions around the world have begun to adopt them actively through programs and educational communities. It is helping them provide hands-on experience in comparison to the traditional method of teaching with just tests and lectures [54, 55]. In (2012), about (90\%) of institutions have provided the first-year seminar and by now many top universities like Elon, Princeton, William's College,
Butler, Yale, Hamline, Harvard, Luther's college, Belmont, and University of California are using HIEPs. This section assesses the HIEPs and core competencies implementation in the University of California and Indiana University using withincase and cross-case analysis [56].

\section{University of California (UC)}

The University was founded in (1869) with just (28) students and (10) faculty members and today boasts of more than (22700) faculties and staffs, (280000) students, and (2) million alumni working around the world [57]. With the mission of serving society with higher learning, discovering new knowledge, providing long-term societal benefits, and functioning as an active repository of organized knowledge, the university includes graduate, undergraduate, or professional education, public services, and research [58].

In order to provide the advanced knowledge experience and work on fulfilling the mission, the UC adopted a competency model with (9) competencies which aimed at serving as a fundamental tool for the development and assessment of managers, leaders, and staff. The UC competency model of (2011) consists of communication, diversity, and inclusion (UC policies on Diversity and Non-Discrimination), Employee engagement, innovation and change management, job mastery and continuous learning, resource management (accountability, integrity, and stewardship as per UC standard of ethical conduct and other policies), results from orientation and execution, service focus, and teamwork and collaboration [59]. However, with the need for evolution in competencies of staff, the model updated to (2020) UC Core Competency Model [59].

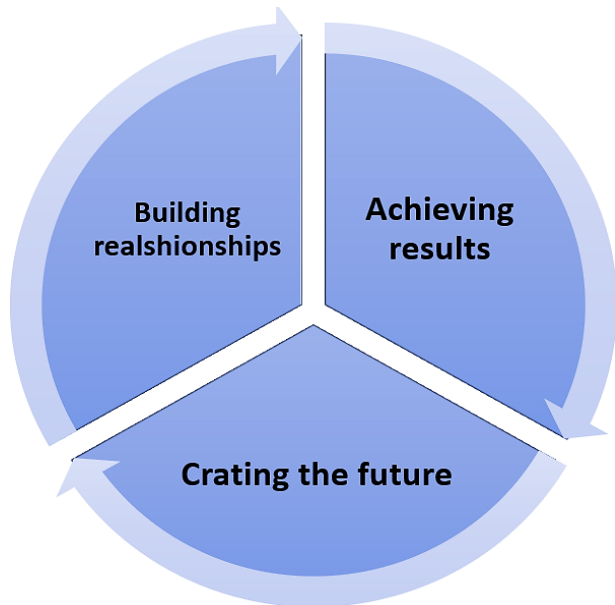

Fig. 2. 2020 UC core competency model

The model evolved to represent $\mathrm{ABCs}$ of core competency i.e. Achieving results (continuous improvement, problem-solving, continuous learning, and service focus), Building relationships (Belonging and community, collaboration, and communication), and Creating the Future (Change agility, mission, and vision focus, and stewardships) [60].

UC considers that HIEPs bring about transformative changes in educational growth, offer increased marketability, and enable the personal development of students and staff. Thus, through the Office of Student Engagement, the university includes practices like research or internship opportunities, 
field-based research projects, research projects, research or study abroad or academic internship opportunity, and servicelearning projects [60]. For this the UC has developed programs like Health Professional Advising Center (provide information, support, and advising to students seeking health professions); undergraduate research programs i.e. development of undergraduate research portal (uResearch) and opportunities like CAMP and MSRIP, undergraduate research symposium (opportunity for sharing creative and research activities) [61], undergraduate research journal (opportunity to feature undergraduate scholarships and researches), and chancellor's research fellowship (competitive award for supporting undergraduate creative activity and research projects); community engagement and service-learning (community service portal developed to connect volunteers with campus departments and non-profit organizations, long term academic internships, service-learning, and group service events); R'Courses (student-initiated course to provide democratic education); Capital academic internship program (opportunity to connect classroom knowledge to workplace); and Prestigious scholarship \& Awards (endorsed, summer research, and prestigious awards) [57, 61].

In (2018), NSSE reported that the UC mentioned that in the examination of first-year students in HIEPs, about (14\%) of them participated in two more HIEPs (Service learning, research with faculty, and learning community) while (44\%) students are part of one HIEP [62]. Even about (77\%) of students plan to participate in internship or field experience programs, $(51 \%)$ in study abroad, and $(56 \%)$ in culminating senior experience. NSSE further revealed that with such practices there are significantly high student engagement in form of higher-order learning, quantitative reasoning, collaborative learning, and effective teaching practices $[62,63]$. These activities helped the university to identify and recruit first-generation students, directing them to appropriate programs, higher GPA, graduation on time possibility, prepared for graduate school or workforce connecting them to more possibilities, and building relationships between mentors and students [57].

\section{Indiana University $(I U)$}

Founded in 1820, Indiana University (IU) is among the first public universities settled in the west of Allegheny Mountain. Beginning classes in (1825), IU represented a progressive commitment towards having diversity and inclusion. In today's scenario, IU community demonstrating cross-section of people from all cultures and background have (9) campuses, more than (71000) undergraduate students, (19000) students in professional and graduate programs, (21000) faculties or staff, (7200) international students from (164) countries, and (725000) IU alumni around the world [64]. Today the University's focus lies in creating a brighter future for students, drive innovation, achieve a breakthrough in DNA technology, and undergoing cancer research for trailblazing resources and cultural programs. IU is a home for world-class academics, shared success, innovation, global perspectives, bold vision, and strong values [65].

One of the focuses of the university is to improve the learning and teaching experience. For this purpose, IU has stated staff competencies for contributing to workplace success in (2019) by paying the foundation for human resource initiatives i.e. career progression, recruitment, training and development, and performance management. It provides employees with a common language to describe what to expect from each other, how to work together, and how to maximize their potential. These competencies define what an employee expect from themselves and others [64].

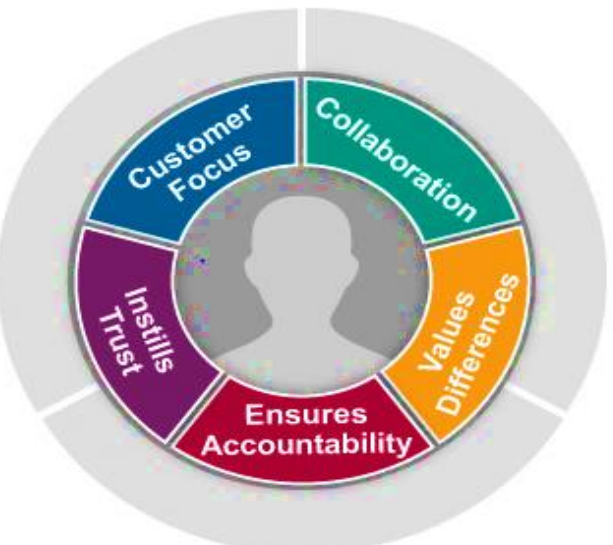

Fig. 3. IU Staff core competencies

Targeting the HR2020 initiative of IU, staff competencies represent the observable behaviors and skills that IU staff should demonstrate, the five core competencies of IU are - Ensure Accountability (holding self and others accountable and responsible to meet commitments), Collaboration (building partnerships and working collaboratively for fulfilling objectives), Instills Trust (gaining trust and confidence via integrity, authenticity, and honesty), Values Differences (value of bringing different cultures and perspectives), and Customer Focus (building external and internal strong relationship and delivery customer-centric solutions) [66].

Further, working on the teaching mechanism, IU has focused on using experimental learning instead of traditional lessons and lectures through internships, capstone projects, undergraduate research, study abroad, or service-learning practices for having an engaging educational experience [67]. NSSE report showed that in IU Northwest with the implementation of HIEP activities i.e. service learning, learning community, and research with faculty, there is only (4\%) students who are participating in two or more HIEPs as mostly (53\%) students are just getting involved in one HIEP [62]. However, about (70\%) of students are planning to participate in internship or field experience, (30\%) study abroad, and (43\%) in culminating senior experience. Due to these mostly first-year students (FY) had a significantly high engagement in learning strategies [63], about (15) hours spent per week studying, (42\%) of FY students believe in involved diverse perspectives in course, $(57 \%)$ rate the high quality of interaction with faculties, $(56 \%)$ of them frequently work with their peer in research projects, $(74 \%)$ consider the availability of learning support services, and $(79 \%)$ consider their educational experience as good [62]. Thus, though HIEPs led to the investment of significant time and effort in IU but better interaction among peers and faculty, and improved learning through constructive 
feedback and real-world applications based learning's were derived [64].

\section{RESULTS}

The survey analysis for the (130) students or faculty members of the Northern Border University was conducted to understand the nature of core competencies and HIEPs implementation. It also aimed to determine the strengths, weaknesses, opportunities, and threats of HIEPs. Examination of the demographical characteristics of respondents is shown below.

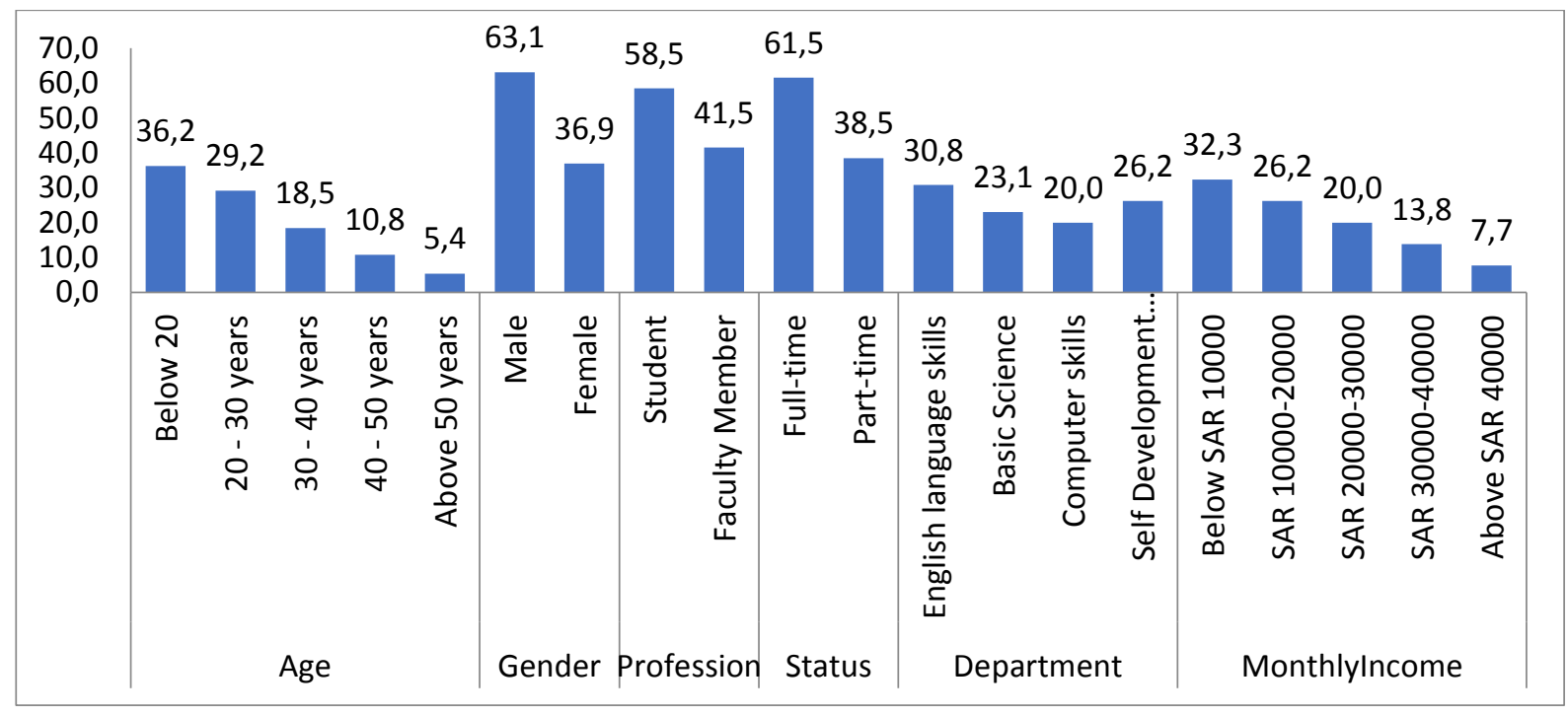

Fig. 4. Demographical analysis of respondents

Above figure shows that most of the respondents are above (20) years i.e. $29.2 \%$ (20-30 years), $18.5 \%$ (30-40 years), $10.8 \%$ (40-50 years), and $5.4 \%$ (above 50 years) wherein about $(63.1 \%)$ are male, while $(36.9 \%)$ as female. The professional level depicts that among the respondents $(58.5 \%)$ are students and $(41.5 \%)$ are faculty members. The status of their involvement in college represents that $(61 \%)$ are full time while $(38.5 \%)$ are part-time. Departments of respondents represent that about $30.8 \%$ are from English language skills, (23.1\%) from basic science, $20 \%$ from computer skills, and remaining (26.2\%) from self-development skills. Monthly income level represents most of the respondents' family income is above SAR (10000) i.e., 26.2\% (SAR 10000-20000), 20\% (SAR 20000-30000), 13.8\% (SAR 30000-40000), and 7.7\% (above SAR 40000).

The examination of the knowledge level of respondents about the HIEPs and core competencies is shown below.

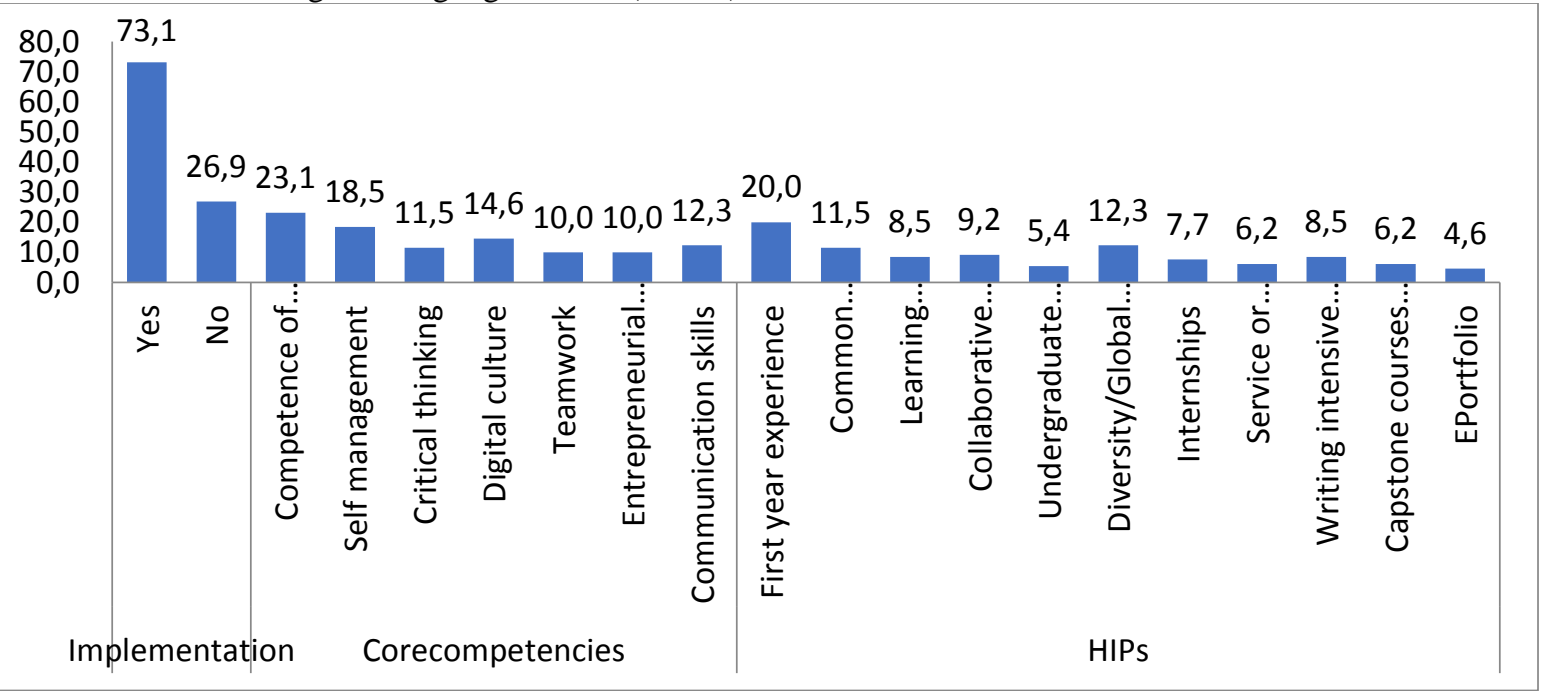


Fig. 5. Status of core competencies and high impact practices implementation

The above figure represents that about (73.1\%) of them believe their institution work on implementing core competencies and HIEPs. Among the core competencies, the competence of Saudi national identity, self-management, and digital culture is the most widely applied competencies while HIEPs of the first-year experience, diversity/global learning, and common intellectual experience is mainly for the preparatory year.

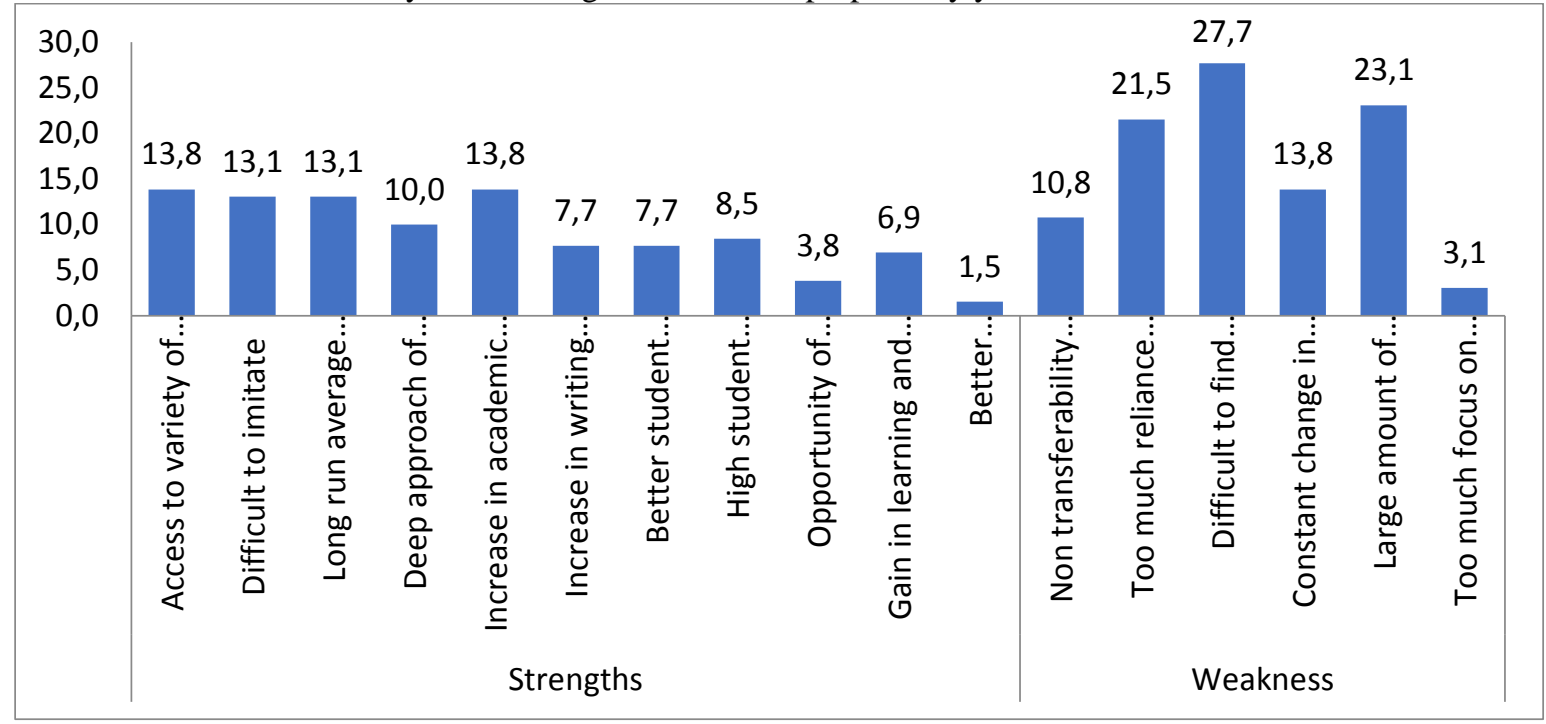

Fig. 6. Perception of strengths and weaknesses of these practices

The examination of the strengths revealed that about $(13.8 \%)$ consider access to various markets and increase in academic performance as the advantage of these activities, (13.1\%) focus on difficult to imitate and long-run average performance, while $(10 \%)$ on the deep approach of learning.
About the weaknesses, (27.1\%) highlighted the difficulty of substitution, $(23.1 \%)$ about a large amount of effort and time spent, while $(21.5 \%)$ on the too much reliance on certain people.

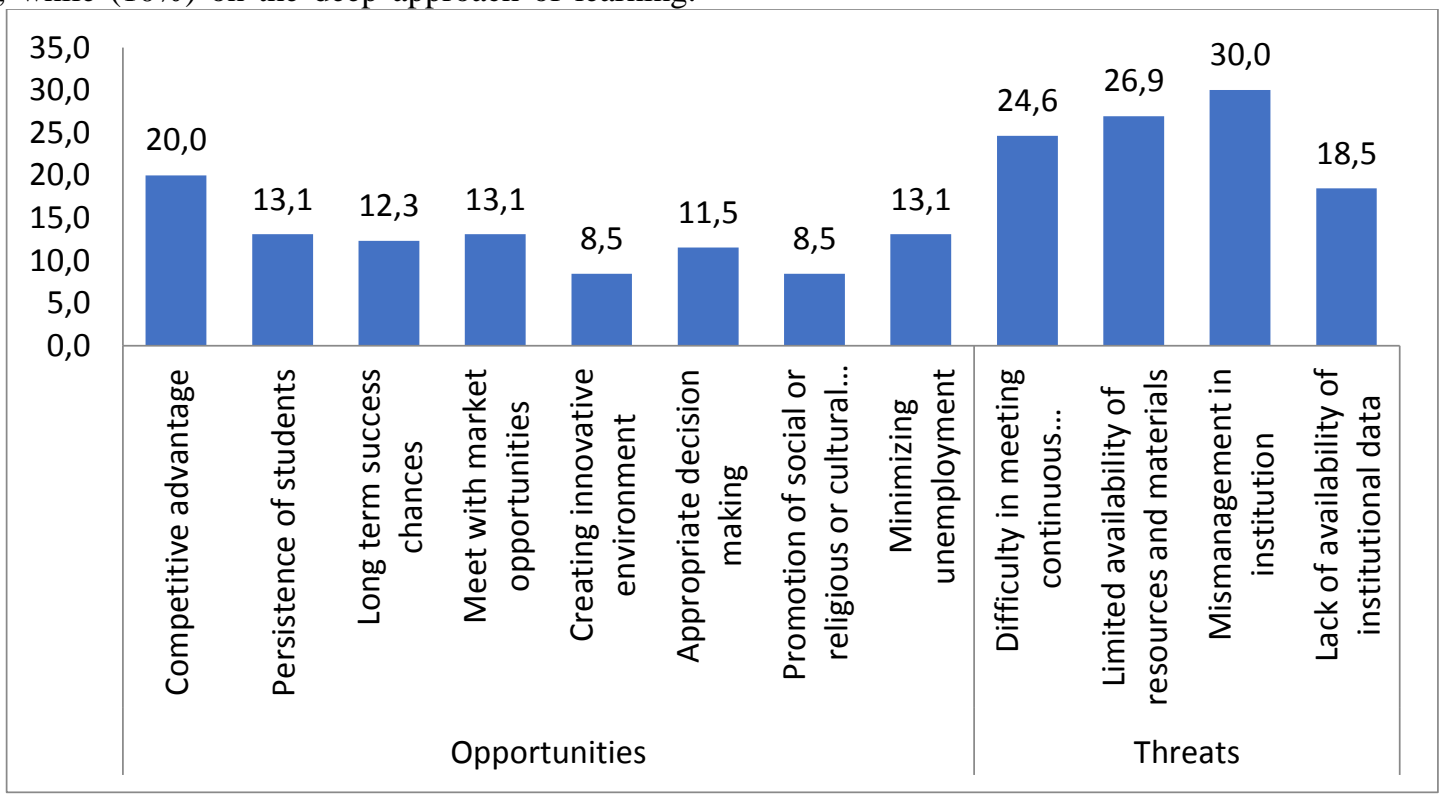

Fig. 7. Perception of opportunities and threats

The perception of the opportunities available from implementing core competencies and HIEPs, about (20\%) consider a competitive advantage, while (13.1\%) mention the persistence of students, meeting market opportunities, and minimizing unemployment. Concerning threats, about (30\%) of them described mismanagement of institution, (26.9\%) about the limited availability of resources and materials, and (24.6\%) about the difficulty in meeting continuous up-gradation needs. 
After identifying the strengths, weaknesses, the impact of these practices on teaching and learning opportunities, and threats of core competencies and HIEPs, due to existing weaknesses and threats, there is a need to understand outcomes. For this, statements on the effect of these practices are coded as shown below.

Table 2.Coding for statements

\begin{tabular}{|l|c|}
\hline \multicolumn{1}{|c|}{ Statements } & Code \\
\hline Practices influence teaching and learning outcome (Dependent). & TLO \\
\hline The activities have improved reading, writing, and critical thinking skills. & CHIP1 \\
\hline Practices have addressed the difference between expert and novice approach to knowledge. & CHIP2 \\
\hline Contributed to explore highly relevant issues and controversies. & CHIP3 \\
\hline Improved the ability to discern credibility and biases of sources. & CHIP4 \\
\hline Courses have improved the ability to organize, articulate, and defend assertions. & CHIP5 \\
\hline Improved the ability to consider multiple perspectives. & CHIP6 \\
\hline Student engagement in local diverse communities off campus improved. & CHIP7 \\
\hline Enabled linking of knowledge and skills across multiple courses. & CHIP8 \\
\hline Helped in building a better bond between students and faculty members. & CHIP9 \\
\hline A deeper understanding of the course material could be derived. & CHIP10 \\
\hline Challenged an individual to think more critically about judgments and the decision-making process. & CHIP11 \\
\hline More financial investment in the courses is required. & CHIP12 \\
\hline
\end{tabular}

The efficiency of each of these statements and their relevance in computing the influence of core competencies and HIEPs on the educational and learning outcome is derived by reliability analysis via Cronbach alpha

Table 3.Reliability analysis

\begin{tabular}{|c|c|}
\hline Number of statements & Total Cronbach alpha value \\
\hline 12 & 0.95 \\
\hline
\end{tabular}

The above table shows that the total Cronbach alpha value is $(0.95>0.7)$, thus the statements are effective enough to represent adequate information about the linkage between variables depicting linkage could be built between independent and dependent variables.

For building in the linkage between statements on HIEPs and core competencies and the learning and teaching outcome, the correlation analysis needs to be done.

Table 4.Correlation analysis

\begin{tabular}{|c|c|c|}
\hline Statements/ Variable & Pearson Correlation & Significance Value \\
\hline CHIP1 & 0.82 & 0.00 \\
\hline CHIP2 & 0.49 & 0.00 \\
\hline CHIP3 & 0.72 & 0.00 \\
\hline CHIP4 & 0.73 & 0.00 \\
\hline CHIP5 & 0.69 & 0.00 \\
\hline CHIP6 & 0.65 & 0.00 \\
\hline CHIP7 & 0.68 & 0.00 \\
\hline CHIP8 & 0.71 & 0.00 \\
\hline CHIP9 & 0.70 & 0.00 \\
\hline CHIP10 & 0.65 & 0.00 \\
\hline CHIP11 & 0.67 & 0.00 \\
\hline CHIP12 & 0.68 & 0.00 \\
\hline
\end{tabular}

The analysis shows that a significant value for all statements is $(0.00<0.05)$, thus there is the possibility of linkage between variables. Further, with the Pearson correlation value of greater than $(0.5)$ for all statements except CHIP2, there is the existence of at least a moderate relationship between HIEPs and core competencies and the teaching and learning outcome. Impact analysis for them is done through regression analysis.

Table 5. Regression analysis 


\begin{tabular}{|c|c|c|c|c|c|c|}
\hline TLO & Coefficient & T-statistic & p-value & $\mathbf{R}^{2}$ & Adjusted $\mathbf{R}^{2}$ & F ratio \\
\hline Constant & -0.16 & -0.94 & 0.35 & 0.83 & 0.81 & 51.14 \\
\hline CHIP1 & 0.48 & 6.19 & 0.00 & & & \\
\hline CHIP3 & 0.13 & 2.43 & 0.02 & & & \\
\hline CHIP4 & 0.16 & 2.79 & 0.01 & & & \\
\hline CHIP5 & 0.03 & 0.55 & 0.59 & & & \\
\hline CHIP6 & -0.07 & -0.96 & 0.34 & & & \\
\hline CHIP7 & 0.04 & 0.52 & 0.60 & & & \\
\hline CHIP8 & 0.15 & 2.38 & 0.02 & & & \\
\hline CHIP9 & 0.20 & 2.73 & 0.01 & & & \\
\hline CHIP10 & -0.03 & -0.48 & 0.63 & & & \\
\hline CHIP11 & 0.25 & 3.21 & 0.00 & & & \\
\hline CHIP12 & -0.27 & -3.10 & 0.00 & & & \\
\hline
\end{tabular}

The $\mathrm{R}^{2}$ and adjusted $\mathrm{R}^{2}$ values of $(0.83)$ and $(0.81)$ reveal that about $(81 \%)$ of the variation in teaching and learning outcome is being represented by these activities. F-ratio value is (51.14 $>1$ ), thus more precision is derived by including respective independent variables. P-value test shows that for CHIP1, CHIP3, CHIP4, CHIP8, CHIP9, CHIP11, and CHIP12 the value is less than (0.05) thus the null hypothesis of Core competencies and High impact educational practices having no significant influence on the teaching and learning outcome is rejected. The coefficient value further shows that with improvement in reading, writing, and thinking skills (CHIP1); exploring of relevant issues and controversies (CHIP3); ability to discern credibility and biases of the source (CHIP4); linking of knowledge and skills (CHIP8); the better bond between students and faculty members (CHIP9); and more critical thinking for judgments and decision-making process (CHIP11) there is a rise in teaching and learning outcome for the Northern Border University.

Thus, the case-based analysis and survey analysis helped in fulfilling the aim of this study (i.e., to determine the impact of HEIPs in preparatory years for Saudi Arabian Universities using the case of Northern Border University). The case-based analysis revealed that international universities do not rely only on the implementation of all theoretical practices. Instead, they follow the process of examining the academic environment for the respective institution and then applying the practices which best fit their university. This way implementation helps in providing better information about the academic structure of the institution along with targeting the students specifically for improving the real-world application of theoretical knowledge and deriving better teacher and student interaction. However, in Northern Border University, the Saudi Arabian University, mostly Saudi national identity, self-management, and digital culture core competencies while first-year experience, diversity/global learning, and common intellectual experience HIEP practices are implemented. These practices help in improving teaching and learning experience by targeting reading, writing, and thinking skills; credibility; linking of knowledge and skills, and students and faculty members' bond. Therefore, Saudi Universities should formulate a plan for having an effective implementation of these practices.

\section{RESULTS DISCUSSION}

The Kingdom of Saudi Arabia is continuously working on providing a high quality of skills and knowledge to students but still the existence of challenges like difficulty in securing resources, meeting the rising demand of students, and adjusting education quality with workforce needs hampers the functioning of higher educational institutions quality. In order to overcome critical challenges facing the country, Saudi Arabia's Vision (2030) is key in creating a world-class university education experience, particularly in preparatory years. Core competencies define the skills required for becoming successful and high impact educational practices are the techniques, which provide deep learning to students. Thus, their implementation in the universities would help in improving the educational experience in Saudi Arabia. Many universities in Saudi Arabia have used preparatory year program for having the better engagement of students with the universities along with providing them with an overview of the academic practices. Herein using the HIEPs like first-year experiences, learning communities, writing-intensive courses, collaborative assignments and projects, and service-learning or community-based learning; the Saudi Arabia higher education university at their preparatory year are working towards enhancing the skill set of individuals through improvising language-based knowledge or personality, building in the connection between students and faculties, providing basic skillset, and influencing the attitude of students.

Focusing on this aspect the case-based analysis was done for international universities (i.e., University of California and Indiana University). The analysis revealed that the international universities instead of applying all the stated core competencies and HIEPs, implement only the suitable practices for their institution. UC educational framework has core competencies of Achieving results, building relationships, and 
Creating the Future while HIEPs activities of Health Professional Advising Center, undergraduate research programs, community engagement and service-learning, R'Courses, Capital academic internship program, and Prestigious scholarship \& Awards. In the case of Indiana University, the core competencies are Ensure Accountability, Collaboration, Instills Trust, Values Differences, and Customer Focus while the HIEPs that are often used for first-year students are Capstone projects, undergraduate research, study abroad, service-learning practices, and learning community. All these practices drive better teacher-student interaction, improve learning and real-world applications of theoretical knowledge.

Further, to evaluate the Saudi Arabian University status the examination of (130) students and faculty members of preparatory year perception is done. With the age and monthly income of mostly above (20) years and SAR (10000) respectively, the respondents state those core competencies of Saudi national identity, self-management, and digital culture while HIEPs of the first-year experience, diversity/global learning, and common intellectual experience are widely implemented for the preparatory year. These activities help in raising access to various markets, increase academic performance, and deep approach to learning along with creating opportunities for competitive advantage, the persistence of students, meeting market opportunities, and minimizing unemployment. However, the difficulty of substitution, the large amount of effort and time requirement, and too much reliance on certain people are the weakness of these practices along with the threat of mismanagement in the institution, limited availability of resources and materials, and difficulty in meeting continuous up-gradation needs. Further, implementation of core competencies and HIEPs by improvement in reading, writing, and thinking skills; exploring of relevant issues and controversies; ability to discern credibility and bias of source; linking of knowledge and skills; the better bond between students and faculty members; and more critical thinking for judgments and decision-making process could improve the teaching and learning experience.

\section{THE PROPOSED IMPLEMENTATION PLAN}

A critical challenge for the Saudi Arabian government is to reduce the country's dependency on oil for generating revenues. For this, the government in partnership with leading universities of the country is including and implementing reformatory initiatives to improve the standard of education in the country. Higher educational institutions in Saudi Arabia are working towards implementing core competencies and high impact educational practices for enriching the learning experience of students and training the faculties to be competent enough to provide the education which helps students in becoming skilled enough to deal with changing job market requirements.

The assessment of the international universities and the Saudi National University educational system state that instead of focusing on all the stated competencies i.e., (7) core competencies and the (11) HIEPs, the international universities utilize their funds in specific targeting of students i.e., as per the educational environment the core competencies and the HIEPs are defined. However, although the Saudi National University implements all the core competencies and HIEPs, there are only certain activities that contribute to influencing the learning and teaching experience. Saudi national universities already bear the threat of difficulty in meeting continuous up-gradation needs, lack of resources and materials available, and mismanagement in the institution. Therefore, there is a requirement that the improvised educational framework should be designed in a personalized way to reduce the threat of these aspects in the quality of education. Thus, a model is proposed for providing a brief overview of the framework, which could be used to enable the effective implementation of core competencies and HIEPs.

Step 1 (Current Status assessment): Aiming to personalize core competencies and HIEPs and implementing them, the examination of the current status needs to be done. This helps in determining the issues that the educational system of a particular institution and compares the performance with the stated (2030) Vision criteria. Thus, the defined themes for working could be teaching and learning, infrastructure and revenue, community engagement, and research and innovation. Step 2 (Documentation): Further, majorly the lack of availability of dataset like total graduates, the retention rate of students, preferences in courses, teaching practices, or the feedback on the courses; is the problem of international and Saudi Arabian universities. Thus, an online portal needs to be created for storing all information and providing easy accessibility that to the faculties.

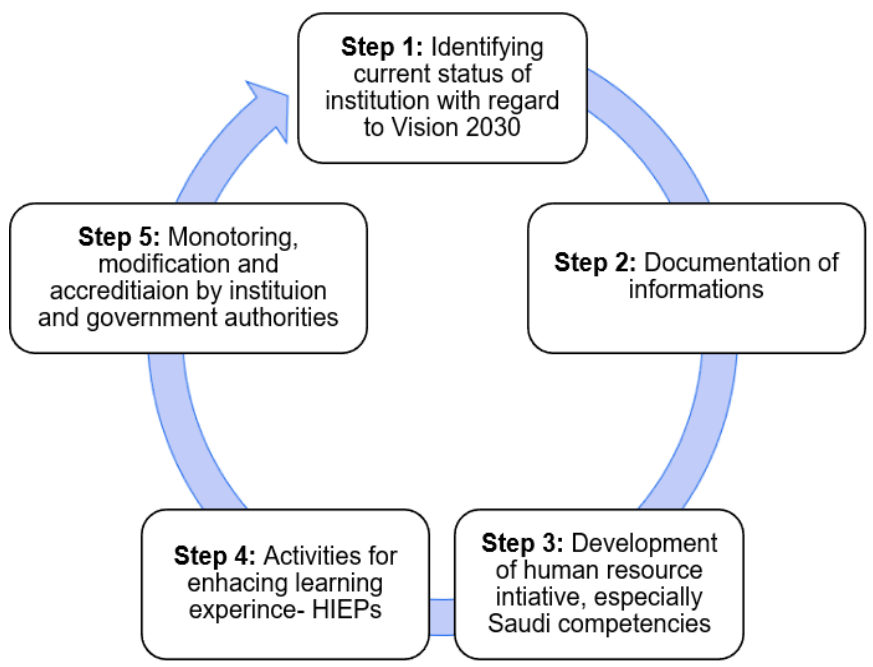

Fig. 8. Proposed Plan for Saudi Arabian Universities

Step 3 (Human Resource Initiative development): The examination of Northern Border University reveals that currently, the competencies i.e., Saudi national identity-based competency, self-management, digital culture, communication skills, and critical thinking are the main aspects. As top international institutions personalize their staff competencies like achieving results, building relationships, and creating a future for UC while collaboration, customer focus, values difference, ensure accountability, and instills trust for IU. Thus, Saudi Universities too need specific designing based on their themes of working and even need initiation of the programs for having the student and staff training. Herein, the HIEPs target the working of the students but for providing education 
effectively, students need to be trained with personal skills, problem-solving, critical thinking, and other technical skills. Even for imbibing these skills among students, the university needs to organize workshops for regularly upgrading the skill set of staff members.

Step 4 (Learning Experience enhancing activities): HIEPs should be implemented because international and Saudi Arabian universities derive more effective benefits by using the experimental marketing technique of teaching instead of traditional lectures. In order to retain students, it is necessary to hold the interest of first-year students. Therefore practices like the first-year experience, global learning, common intellectual experience, service learning, researches, and learning community should be implemented through building advising centers, building up of undergraduate research portal and providing research-based scholarships, community portal building for providing services, blending the traditional knowledge with online courses, creating a smart learning environment, developing programs in health professions, and creating a virtual space for Alumni meet.
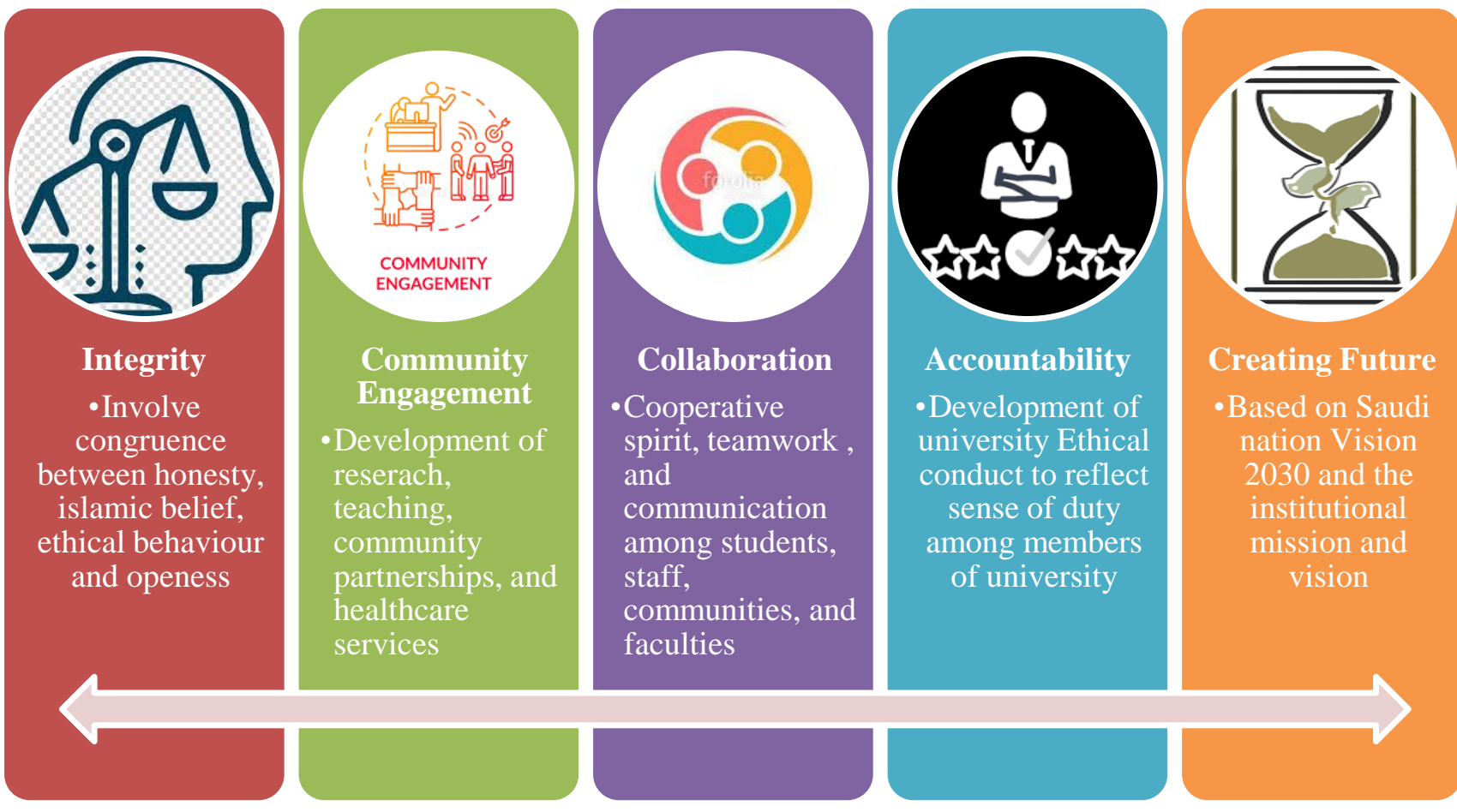

Fig. 9. Core Competencies of Saudi Universities

\section{CONCLUSION AND FUTURE WORK}

The goal of the conducted study is to assess the impact of high-impact educational practices in Saudi universities and international universities as well, then propose an efficient plan for efficiently implementing high-impact educational practices in higher education institutions. Case-based analysis and the survey analysis method were used wherein qualitative examination of practices in University of California and Indiana University and quantitative assessment of (130) faculty members and students' perception of Northern Border University were conducted.
Step 5 (Monitoring, Modifying, and Accreditation): Based on the restructuring of the programs as per defined standards, core competencies, and HIEPs; the regular monitoring of the teaching and learning experience needs to be done by semiannual survey. Further, a discussion session should be organized to review the feedbacks and state the changes that are required in the educational framework. Lastly, a program should be launched at the national level to review the status of Vision (2030) implementation in higher educational institutions based on which ranking needs to be provided. Even the internal committee should be developed for regularly reviewing the development status of the institute.

Thus, the above-stated plan implementation in higher educational institutions will enable the implementation of core competencies and HIEPs in the Saudi Arabian universities and having their significant contribution in the advancement of teaching and learning experience along with benefitting the economy by the rise in educational status. 
novel plan for implanting high impact educational practices, consisting of five main steps: (i) identifying the status of the institution with regard to vision (2030), (ii) documentation of information, (iii) development of human resource initiative, especially Saudi competencies, (iv) activities for enhancing the learning experience and $(\mathrm{v})$ monitoring, modification and accreditation by an institution and government authorities. This plan might be generalized to be implemented in any global education institution, which is looking toward applying highimpact educational practices.

However, the study covered the international experience and Saudi Arabian universities status on core competencies and HIEPs, the lack of statistical examination of international experience and the small sample size of students and faculty members is the limitation for this study. Thus, further studies could work towards broadening the scope of the study by examining the perception of faculty members and students on core competencies and HIEPs in top international universities. Moreover, future studies can add to this area of research by assessing the impact of core competencies and HIEP on student engagement and retention, in all higher education levels rather than only preparatory years.

\section{ACKNOWLEDGMENTS}

The authors extend their appreciation to the Deputyship for Research \& Innovation, Ministry of Education in Saudi Arabia for funding this research work through the project number "IF_2020_4326".

\section{REFERENCES}

[1] Hadiyanto, H. Higher Education: A Suggestion Model for Universities in Indonesia. EDUCARE: International Journal for Educational Studies, 2010; 3(1): 11-22.

[2] Morris, P. D., M.Cobb, C., S. Higgs, M. A. High-Impact Practices and the Adult Online Learner. World Journal of Educational Research. 2019; 6(4): 463-469.

[3] Gontareva, I, Maryna, B, Babenko, V, Perevozova, I, Mokhnenko, A. Identification of Efficiency Factors for Control over Information and Communication Provision of Sustainable Development in Higher Education Institutions, WSEAS Transactions on Environment and Development, 2019; 16(63): 593-604.

[4] Kotina, H, Stepura, M Fedosov, V, Hrysohlazov, D, Bilinets, M. Competitiveness of Higher Education in Ukraine and Certain European Countries: Empirical Studies on Funding and Academic Attractiveness. WSEAS Transactions on Business and Economics, 2020; 17(83): 849-858.

[5] Trifonov, R, Tsochev, G, Nakov, O, Pavlova, G, Manolov, S. Possibilities for Improving the Quality of Cyber Security Education through Application of Artificial Intelligence Methods. Engineering World, 2020; 2: 145149.

[6] Alkhazim, M. Higher education in Saudi Arabia: Challenges, solutions, and opportunities missed. Higher Education Policy. 2003; 16(4): 479-486.

[7] Alharbi, E. Higher education in Saudi Arabia: Challenges to achieving world-class recognition. International of
Journal of Culture and History. 2019; 2(4): 169-172.

[8] Best Preparatory Year programs 2021 [Internet]. Academiccourses.com. [cited 2021 Jan 25]. Available from: https://www.academiccourses.com/PreparatoryYear/Programs/.

[9] Alblowi A. An evaluation of the effectiveness and validity of the preparatory year programme in preparing students for studying in Taibah University in Saudi Arabia [Doctoral dissertation]. Dublin: Dublin City University; 2016.

[10] Morris, A. K., \& Hiebert, J. Effects of teacher preparation courses: Do graduates use what they learned to plan mathematics lessons?. American Educational Research Journal. 2017; 54(3): 524-567.

[11] Kuh A, George D. Excerpt from high-impact educational practices: What they are, who has access to them, and why they matter. Association of American Colleges and Universities. 2008;14(3): 28-29.

[12] Northern Border University. Rosettastone.com. [cited 2021 Jan 25]. Available from: https://resources.rosettastone.com/assets/lp/9999999999/r esources/case-study-northern-border-university.pdf.

[13] Saqlain, N., \& Mahmood, Z. (2013). English Language Instructors' Perceptions about Technology-Based Language Learning at Northern Border University in Saudi Arabia. Turkish Online Journal of Educational Technology-TOJET. 2013; 12(2): 106-110.

[14] TechTarget Contributors. Core competency (core competencies) [Internet]. Techtarget.com. TechTarget; 2017 [cited 2021 Jan 25]. Available from: https://searchcio.techtarget.com/definition/corecompetency.

[15] ILO. Skills strategies for future labour markets (SKILLS). [cited 2021 Jan 25]; Available from: https://www.ilo.org/skills/areas/skills-training-forpoverty-reduction/lang--en/index.htm.

[16] Al Alharbi, M. Case study of the impact of using technology in Saudi Arabia primary school in support of teaching and learning with regard to the English curriculum. The Online Journal of Science and Technology.2019; 9(2): 98-105.

[17] Alqarni, A. Educational technology in Saudi Arabia: a historical overview. International Journal of Education, Learning and Development. 2013; 3(8): 62-69.

[18] Alrashidi, O., \& Phan, H. Education Context and English Teaching and Learning in the Kingdom of Saudi Arabia: An Overview. English Language Teaching. 2015; 8(5): 33-44.

[19] Montana-Hoyos C, Stracke E, Oerlemans K, Pianca E, Trathen S. Curriculum in Progress: Developing an industrial design programme for female students in Saudi Arabia. In DS 83: Proceedings of the 18th International Conference on Engineering and Product Design Education (E\&PDE16), Design Education: Collaboration and CrossDisciplinarity. Aalborg, Denmark; 2016. p. 210-215.

[20] Chan, C. K., Fong, E. T., Luk, L. Y., \& Ho, R. A review of literature on challenges in the development and implementation of generic competencies in higher education curriculum. International Journal of Educational Development. 2017; 1(57): 1-10. 
[21] Washer P. Revisiting key skills: A practical framework for higher education. Quality High Education. 2007; 13(1):57-67.

[22] Bhasin H. Core competencies - importance, advantages and limitations [Internet]. Marketing91.com. 2015 [cited 2021 Jan 25]. Available from: https://www.marketing91.com/core-competency/.

[23] Masud M. Core competencies: Examples, explanation and advantages [Internet]. Advergize.com. 2018 [cited 2021 Jan 25]. Available from: https://www.advergize.com/marketing/corecompetencies-examples-explanation-advantages/.

[24] Albarqouni, L., Hoffmann, T., Straus, S., Olsen, N. R., Young, T., Ilic, D., et al. Core competencies in evidencebased practice for health professionals: consensus statement based on a systematic review and Delphi survey. JAMA Network Open. 2018; 1(2): 151-168.

[25] Faiz, M. A. Organization's Core Competencies; A Key for Successful \& Happy Organization. International Journal of Accounting \& Business Management. 2014; 2(1): 6-16.

[26] High-Impact Educational Practices [Internet]. Aacu.org. 2014 [cited 2021 Jan 25]. Available from: https://www.aacu.org/node/4084.

[27] High impact practices (HIPs) or engaged learning practices [Internet]. Uwaterloo.ca. 2013 [cited 2021 Jan 25]. Available from: https://uwaterloo.ca/centre-forteaching-excellence/support/integrative-learning/highimpact-practices-hips-or-engaged-learning-practices.

[28] High-Impact Practices [Internet]. Uwec.edu. [cited 2021 Jan 25]. Available from: https://www.uwec.edu/acadaff/academic-masterplan/high-impact-practices/. UW-Eau Claire. (2020).

[29] Christenson SL, Thurlow ML. School dropouts: Prevention considerations, interventions, and challenges. Current Directions in Psychological Science. 2004;13(1):36-9.

[30] Rumberger RW, Rotermund S. The relationship between engagement and high school dropout. In: Handbook of Research on Student Engagement. Boston, MA: Springer US; 2012. p. 491-513.

[31] Truta C, Parv L, Topala I. Academic engagement and intention to drop out: Levers for sustainability in higher education. Sustainability. 2018;10(12):4637.

[32] Montelongo R. Less than/more than: Issues associated with high impact online teaching and learning. Administrative Issues Journal Education Practice and Research [Internet]. 2019; 9(1). Available from: http://dx.doi.org/10.5929/9.1.5.

[33] Use High Impact Practices [Internet]. Colorado.edu. 2020 [cited 2021 Jan 25]. Available from: https://www.colorado.edu/center/teaching-

learning/inclusivity/inclusive-pedagogy/use-high-impactpractices.

[34] Kuh, G., O'Donnell, K., \& Schneider, C. G. HIPs at ten. Change: The Magazine of Higher Learning. 2017; 49(5): 8-16.

[35] Kuh, G. D., Kinzie, J., Schuh, J. H., \& Whitt, E. J. Fostering student success in hard times. Change: The magazine of higher learning. 2011; 43(4): 13-19.

[36] Edwards NR, Mindrila DL. Improving graduation rates:
Legitimate practices and gaming strategies. Education policy analysis archives. 2019; 27:41.

[37] Maybe Not So "High Impact"? [Internet]. insidehighered.com 2018 [cited 2021 Jan 25]. Available from:

http://ttps://www.insidehighered.com/news/2018/04/25/st udy-questions-whether-high-impact-practices-yield-

higher-graduation-rates.

[38] High Impact Practices [Internet]. Otl.du.edu. [cited 2021 Jan 25]. Available from: https://otl.du.edu/advance-mypractice/integrative-learning/high-impact-practices/.

[39] Foote, S. Getting HIP: Understanding the how and why of high-impact educational practices [Internet]. Kennesaw.edu. [cited 2021 Jan 25]. Available from: https://cetl.kennesaw.edu/getting-hip-understanding-howand-why-high-impact-educational-practices.

[40] Agha S, Alrubaiee L, Jamhour M. Effect of core competence on competitive advantage and organizational performance. International Journal of Business and Management. 2011;7(1): 3-9.

[41] Sweat, J., Jones, G., Han, S., \& Wolfgram, S. M. How Does High Impact Practice Predict Student Engagement? A Comparison of White and Minority Students. International Journal for the Scholarship of Teaching and Learning. 2013; 7(2): 2-17.

[42] Kilgo, C. A., Sheets, J. E., \& Pascarella, E. T. Do highimpact practices actually have high-impact on student learning? Some initial findings. In: Association for the Study of Higher Education. St. Louis, MO; 2013.

[43] Jabbouri, N. I., \& Zahari, I. (2014). The role of core competencies on organizational performance: an empirical Study in the Iraqi Private Banking Sector. European Scientific Journal, 2014; 1(4): 130-139.

[44] Murray AL. The Academic Library and High-Impact Practices for Student Retention: Perspectives of Library Deans [Internet]. [Bowling Green, Kentucky ]: Western Kentucky University; 2014. Available from: https://digitalcommons.wku.edu/cgi/viewcontent.cgi?arti cle $=1056 \&$ context $=$ diss .

[45] Elmahdi, I., Muammar, O., \& Al-Hattami, A. The Effect of a Core Competencies Training Program on Faculty Members' Teaching Performance. International Journal of Pedagogical Innovations. 2015; 3(02): 15-34.

[46] Gipson J, Mitchell D Jr. How high-impact practices influence academic achievement for African American college students. Journal Committed to Social Change on Race and Ethnicity. 2019; 3(2):123-44.

[47] Shavers, C. L., \& Mitchell, R. B. High-Impact Educational Experiences in Colleges of Business. e-Journal of Business Education and Scholarship of Teaching. 2019; 13(1): 1-12.

[48] Creswell, J. Educational research: Planning, conducting, and evaluating quantitative and qualitative research. 4th ed., Boston: Pearson, 2012.

[49] Field, A. Discovering statistics using SPSS. 4th ed., Sage, London, 2009.

[50] Yong, T, Shi-Hua, M, \& Feng-Mei, G. An empirical research: relationship between logistics capabilities and supply chain performance in industrial enterprises'. Chinese Journal of Management, 2007; 4(4), 493. 
[51] Green, S \& Salkind, N. Using SPSS for Windows and Macintosh: Analyzing and understanding data. PrenticeHall, 2012.

[52] Rattray, J, \& Jones, M. Essential elements of questionnaire design and development. Journal of clinical nursing, 2007; 16(2), 234-243.

[53] Kapoor DR. Research methodology methods \& techniques. New Delhi, India: Regal Publications; 2013.

[54] Gomm R, Hammersley M, Foster P, editors. Case study method: Key issues, key texts. London, England: SAGE Publications; 2013.

[55] Comevo. A look at the top 5 ranked institutions for firstyear experience [Internet]. Comevo.com. 2018 [cited 2021 Jan 25]. Available from: https://www.comevo.com/looktop-5-ranked-institutions-first-year-experience.

[56] Comevo. How to implement high impact practices [Internet]. Comevo.com. 2018 [cited 2021 Jan 25]. Available from: https://www.comevo.com/implementhigh-impact-practices.

[57] Artis, D., Wagner, L., \& Miles, L. R. UC first generation breakout session high impact practices. Retrieved from https://diversity.universityofcalifornia.edu/files/document s/uc-first-generation-breakout-session-high-impactpractices.pdf.

[58] UI university Mission [Internet]. Ucop.edu. [cited 2021 Jan 25]. Available from: https://www.ucop.edu/mission/.

[59] The UC System [Internet]. Universityofcalifornia.edu. 2019 [cited 2021 Jan 25]. Available from: https://www.universityofcalifornia.edu/uc-system.

[60] Thompson, L. M., Zablotska, L. B., Chen, J. L., Jong, S., Alkon, A., Lee, S. J., \& Vlahov, D. Development of quantitative research skills competencies to improve doctor of philosophy nursing student training. Journal of Nursing Education. 2018; 57(8): 483-488.

[61] Gonzalez, C. Undergraduate research, graduate mentoring, and the university's mission. Science. 2001; 293(5535): $1624-1626$.
[62] NSSE. NSSE 2018 Engagement Indicators Indiana University Northwest. Retrieved from https://www.iun.edu/institutional-

effectiveness/docs/NSSE

Reports/NSSE18_Engagement_Indicators_IUN.pdf.

[63] NSSE. NSSE 2018 Engagement Indicators Indiana University Northwest. Iun.edu. [cited 2021 Jan 25]. Available from: https://www.iun.edu/institutionaleffectiveness/docs/NSSE\%20Re-

ports/NSSE18_Engagement_Indicators_IUN.pdf.

[64] The Trustees of Indiana University. [Internet]. Indiana.edu. [cited 2021 Jan 25]. Available from: https://www.iu.edu/about/index.html.

[65] Assessing Quality and Equity in High-Impact Practices (HIPs) project [Internet]. Indiana.edu. [cited 2021 Jan 25]. Available from: https://nsse.indiana.edu/research/specialprojects/hip-quality/index.html.

[66] Nolan B. IU HR introduces first phase of staff competencies [Internet]. News.iu.edu. 2019 [cited 2021 Jan 25]. Available from: https://news.iu.edu/stories/2019/02/iu/inside/20-humanresources-introduces-core-staff-competencies.html.

[67] Winkler C. School of education [Internet]. Indiana.edu. [cited 2021 Jan 25]. Available from: https://education.indiana.edu/newsevents/_news/2018/jul-dec/2018-11-16-high-impactpractices.html.

\section{Creative Commons Attribution License 4.0 (Attribution 4.0 International, CC BY 4.0)}

This article is published under the terms of the Creative Commons Attribution License 4.0

https://creativecommons.org/licenses/by/4.0/deed.en_US

\section{Appendix 1 \\ Survey Questionnaire \\ Section A: Demographic Profile}

1. What is your age?
a) Below 20
b) $20-30$
c) $30-40$
d) $40-50$
e) Above 50

2. What is your Gender?

a) Male

b) Female

3. What is your profession?

a) Student

b) Faculty member

4. What is your professional status?

a) Full Time

b) Part-Time
5. Which department you are in?

a) English Language Skills Department

b) Basic Sciences Department

c) Computer Skills Department

d) Self-Development Skills Department

6. What is your family's monthly income?
a) Below SAR 10000
b) SAR $10000-20000$
c) SAR $20000-30000$
d) SAR $30000-40000$
e) Above SAR 40000

\section{Section B: Background Profile}

7. Does your institution work on implementing core competencies and high impact educational practices?

a) Yes 
b) No

8. What according to you are core competencies implemented by your organization?
a) Competence of the Saudi national identity
b) Efficiency of self-management
c) Efficiency of critical thinking
d) Efficiency of digital culture
e) Efficiency of teamwork
f) Entrepreneurial competence
g) The skill of communication

9. What according to you are the high-impact educational practices implemented by your organization?
a) First-year experiences
b) Common intellectual experience
c) Learning communities
d) Writing-intensive courses
e) Collaborative assignments and projects
f) Undergraduate research
g) Diversity/global learning
h) Internships
i) Service-learning or community-based learning
j) Capstone courses and projects
k) e-Portfolios

10. What according to you is the strength of using core competencies and high impact educational practices?
a) Access to a variety of markets
b) Difficult to imitate.
c) Long run above-average performance
d) The deep approach to learning
e) Increase in academic performance.
f) Increase in writing and critical thinking skills
g) Better student-faculty interaction
h) High student engagement
i) The opportunity of applying the theoretical knowledge to real-world
j) The gain in learning and personal development
k) A better understanding of information

11. What according to you are the weakness of using core competencies and high-impact educational practices?
a) Non-transferability of skills
b) Too much reliance on certain people
c) Difficulty to find a substitution

d) Require a constant change in a reward system to motivate faculties

e) A large number of efforts and time spent

f) Too much focus on these practices hampers the learning experience

12. What according to you are the opportunities available by implementing core competencies and high-impact educational practices?

a) Competitive advantage

b) Persistence of students

c) Long term success chances

d) Meet with market opportunities

e) Creating innovative environment

f) Appropriate decision making

g) Promotion of social or religious or cultural diversity

h) Minimizing unemployment

13. What according to you are the threats while implementing core competencies and high-impact educational practices?

a) Difficulty in meeting continuous up-gradation need

b) Limited availability of resources and materials

c) Mismanagement in institution

d) Lack of availability of institutional data

Section C: Impact of Core competencies and High impact educational practices on teaching and learning outcomes

Rate the following based on your perception of the role of core competencies and high impact educational practices on teaching and learning outcomes on a scale of 1-5 where 1 Strongly Disagree, 2 - Disagree, 3 - Neutral, 4 - Agree, and 5 - Strongly Agree

14. Do you think that the core competencies and highimpact educational practices influence teaching and learning outcomes?
a) Strongly disagree
b) Disagree
c) Moderate
d) Agree
e) Strongly agree

\begin{tabular}{|c|c|c|c|c|c|c|}
\hline No. & Statement & 1 & 2 & 3 & 4 & 5 \\
\hline 1 & The activities have improved reading, writing, and critical thinking skills & & & & & \\
\hline 2 & Practices have addressed the difference between expert and novice approach to knowledge & & & & & \\
\hline 3 & Contributed to exploring highly relevant issues and controversies & & & & & \\
\hline 4 & Improved the ability to discern credibility and biases of sources & & & & & \\
\hline 5 & Courses have improved the ability to organize, articulating, and defend assertions & & & & & \\
\hline 6 & Improved the ability to consider multiple perspectives & & & & & \\
\hline 7 & Student engagement in local diverse communities off campus improved & & & & & \\
\hline 8 & Enabled linking of knowledge and skills across multiple courses & & & & & \\
\hline 9 & Helped in building a better bond between students and faculty members & & & & & \\
\hline 10 & A deeper understanding of the course material could be derived & & & & & \\
\hline 11 & Challenged an individual to think more critically about judgments and decision-making process & & & & & \\
\hline 12 & More financial investment in the courses is required & & & & & \\
\hline
\end{tabular}

